\title{
Obsesif Kompulsif Bozuklukta EMDR Terapinin Etkisi: Olgu Sunumu
}

\author{
Serkan Cengiz 1 Âdem Peker ${ }^{2}$
}

\section{Öz}

Obsesif kompulsif bozukluklarda (OKB) ilaç tedavisi ile birlikte alınacak psikoterapi desteğinin iyileşme sürecine olumlu katkılar sağladığı bilinmektedir. Çocukluk döneminde yaşanan olumsuz yaşantılar ve bu yaşantıların işlenmesi noktasında yaşanan sıkıntıların gelecekte olumsuz yaşam olaylarında kendini gösterebileceği ve bireyde farklı psikolojik rahatsızlıklara sebep olabileceği anlayışı göz hareketleri ile duyarsızlaştırma ve yeniden işleme (EMDR) terapinin psikolojik sorunlara bakış açısının temelini oluşturmaktadır. Bu çalışma ile birlikte obsesif düşüncelere sahip bireye EMDR terapi tekniği kullanılarak yapılan danışma oturumları özetlenmiştir. Kadın danışan 22 yaşında ve üniversite öğrencisidir. Terapiye gelme nedeni, genel bir terapi planlaması formuna yazılmış olup her olumsuz anısı için birer çalışma kağıdı doldurulmuştur. EMDR terapinin genel bir tanıtımı ile başlanan sürece, anıların işlenmesi amacıyla EMDR terapi protokolünde yer alan basamakların uygulanması ile devam edilmiştir. Toplam yedi seans süren terapi süreci sonrasında bireydeki iyileşme süreci ele alınmış olup yapılan kontrol seansında bireyde yaşanan sorunlarda azalma olduğu, kendini daha huzurlu hissettiği belirtilmiştir. Kısa sürede olumlu sonuçlar vermesi terapinin uygulanabilirliği ve işlevselliğini desteklemekte, sonraki benzer vakalarda faydalanılabilecek bir olgu sunumu olması bakımından önemli olduğu düşünülmektedir.

Anahtar Sözcükler: Emdr, obsesif kompulsif bozukluk, psikoterapi, anı

\begin{abstract}
Psychotherapy support in combination with pharmacotherapy of obsessive compulsive disorder (OCD) treatment in obsessive compulsive disorders is known to contribute positively to the healing process. The understanding that negative lives experienced in childhood and the difficulties experienced at the point of processing these lives can manifest itself in negative life events in the future and cause different psychological disorders in the individual is the basis of the view of psychological problems of desensitization and reprocessing therapy (EMDR) with eye movements. With this study, counseling sessions conducted using EMDR therapy technique are summarized for individuals with obsessive thoughts. Female client is a 22 years old and university student. The reason for coming to therapy is written in a general form of therapy planning and a working paper is filled for each negative memory. As long as emdr therapy began with a general presentation, it continued with the implementation of the steps in the EMDR therapy protocol for the processing of memories. After a total of seven sessions of therapy, the healing process in the individual was discussed and it was stated that there was a decrease in the problems experienced in the individual during the control session and felt more peaceful. It is thought that it is important to provide positive results in a short time and to support the applicability, functionality of therapy and to be a case report that can be used in subsequent similar cases.
\end{abstract}

Keywords: Emdr, obsessive compulsive disorder, psychotherapy, memory

${ }^{1}$ Serkan Cengiz, Öğretmen, Rehberlik ve Araştırma Merkezi, srkn_cngz_25@hotmail.com

2 Âdem Peker, Doç. Dr. Atatürk Üniversitesi, adem.peker@atauni.edu.tr 


\section{Giriş}

İnsanlar yaşamları boyunca karşılaştıkları olaylara, durumlara çeşitli anlamlar yükleyebilmektedirler. Yaşanılan olaylar veya durumlar kişiyi olumsuz etkilediğinde bireyde olumsuz türde kendilik algısı oluşturabilmektedir. Bireyin kendisine yönelik olumsuz inançlarından, başvurduğu çıkış yollarından biriside obsesif kompülsif bozukluk (OKB) yani takıntı bozukluğudur (Yörük ve Tosun, 2015). Obsesyon, bireyin zihninden uzaklaştıramadığı, kontrolü altına alamadığı, çoğu zaman tehdit edici, ısrarcı ve tekrarlayıcı düşünceler olarak adlandırılırken, kompulsiyon çoğu zaman obsesyona tepki olarak ortaya çıkan davranışlardır (Sinici, Aydın ve Öznur, 2018). En sık görülen obsesif düşünceler; cinsellik, saldırganlık, kirlilik üzerineyken, sık görülen kompülsif düşünceler; yıkanma, biriktirme ve kontrol etme üzerine olan eylemlerdir (Fisher ve Wells, 2005). Bireye rahatsızlık veren takıntılı düşünceler ve bu düşünceleri azaltmak adına tekrarlanan eylemler, bireyin zamanını almakta ve yaşam kalitesini düşürmektedir. Yaşanan bu sürecin ilerlememesi ve bireyin ruh sağlığında daha fazla olumsuzluklara yol açmaması için, iyileştirici hizmetlerden bir an önce faydalanması gerekmektedir.

OKB tedavisine yönelik çağdaş kuram yaklaşımları, sıklıkla ilaç ve psikoterapi desteğinin birlikte alınması halinde iyileşmenin daha hızlı sürede gerçekleşebileceğini desteklemişlerdir (Clark ve Taylor, 2009). Özellikle de bilişsel davranışçı terapi yaklaşımında yer alan maruz bırakma ve tepkiyi önleme tekniklerinin OKB tedavisinde etkili olduğu ifade edilmektedir (Anderson ve Rees, 2007; Beşiroğlu, 2016; Roiser, Elliot ve Sahakian, 2012). Fakat verilen ödevleri yapmakta, korktuğu durum ve düşüncelerle yüzleşmekte kaygılı olan çoğu danışanda bilişsel davranışçı terapi yönteminin faydalı olmadığı da belirtilmektedir (Maher ve Theodore, 2012). Böyle durumlarda alternatif psikoterapi yaklaşımlarına başvurulabilmektedir. Son yıllarda birçok psikiyatrik bozukluk için hızlı ve etkili tedavi yöntemi sunan ve Amerikan psikiyatri birliği tarafından da önerilen (2004), göz hareketleri ile duyarsızlaştırma ve yeniden işleme (EMDR) terapinin, yöntem ve teknikleri, kriz sonrası ortaya çıkan travmalar ile birlikte depresif belirtiler, anksiyete belirtileri, düşük özsaygı, öfke ve suçluluk gibi farklı bozuklukların tedavisi sürecinde de yaygın olarak kullanılabilmektedir (Barker ve Barker, 2007; Kavakçı, 2014; Van den Berg ve Van der Gaag, 2012).

Yapılan araştırmalar incelendiğinde, Konuk, Knipe, Eke, Yüksek, Yurtsever ve Ostep (2006), 1999 Marmara depremi sonrasında, travmaya bağlı stres bozukluğu yaşayan 47 kişiye, ortalama beş seans 90 dakikalık EMDR terapi uygulamışlar ve katılımcıların bildirimine göre stres bozukluğu belirtilerinde belirgin azalma olduğunu bulmuşlardır. Krupnik (2018), dirençli depresyon tanısı olan yirmi bir kişiye, iki oturum EMDR terapi uygulamıştır. Terapi sonucunda bireylerin depresyon puan ölçeklerinde azalma olduğu gözlemlenmiştir. OKB tedavisinde, EMDR uygulamalarına yönelik yapılan araştırmada, Nazari, Momeni, Jariani ve Tarrahi, (2011), tedaviye direnç gösteren OKB' li 
hastalar üzerinde emdr terapinin etkililiğini ortaya koymak amacıyla bir araştırma gerçekleştirmişlerdir. Araştırmada EMDR terapi, bilişsel davranışçı terapi ile birlikte ve tek başına farklı hasta gruplarına uygulanmıştır. Sonuç olarak EMDR terapinin tek başına uygulandığı hastaların, bilişsel davranıcı yaklaşım uygulandığı hastalara göre direnç düzeyinde daha fazla azalma olduğu gözlemlenmiştir. Benzer araştırmada, Marsden, Lovell, Blore, Ali ve Delgadillo (2018), EMDR terapiye bağlı göz hareketleri ile bilişsel davranış̧̧ı terapinin maruz bırakma tekniğinin, OKB tedavisinde etkililiğini kıyasladığı bir çalışmada, emdr terapinin rutin klinik bakımda bilişsel davranışçı terapiye kıyasla daha kısa sürede uygulandığını, daha hızlı iyileşme belirtileri verdiğini bildirmişlerdir.

EMDR terapi, bilişsel, davranışsal, psikodinamik ve danışan merkezli gibi çok iyi bilinen terapi yaklaşımlarının farklı öğelerini bir araya getiren bir tedavi yaklaşımı olarak bilinmektedir (Shapiro 2016). Francine Shapiro tarafından geliştirilen ve travma sonrası stres bozukluğu tedavisinde kullanılan EMDR terapi ile birlikte beynin iki tarafı da harekete geçirilmekte ve yaşanan travmatik olayın gelecekte rahatsızlık vermemesi adına işlenmesi sağlanmaktadır (Shapiro, 2012).

Shapiro, kendisine rahatsızlık veren düşüncelerin bir süre sonra kendisini rahatsız etmediğini anladığında bu durumun kaynă̆ı olarak gözlerinin kendiliğinden yukarıya ve aşağıya doğru istemsiz bir şekilde hareket etmesi ile ilişkilendirmiştir. Bu yöntemi aklına gelen olumsuz düşüncelerden kurtulmak adına uyguladığında işe yaradığını görmüş ve benzer yöntemi 70 denek üzerinde uygulayarak göz hareketleri ile duyarsızlaştırma adını vermiştir (Duman, Bayram ve Demirtaş, 2018). Daha sonraları klinisyenlere verdiği eğitimlerden gelen dönütlerde, anılar ve olumsuz yüklemelerin aynı anda işlenmesi ve bilişlerin yeniden yapılandırılması gerekliliğini fark etmiştir. Bunun üzerine yöntemini göz hareketleri ile duyarsızlaştırma ve yeniden işleme olarak düzenlemiştir (Shapiro, 2007).

$\mathrm{Bu}$ yaklaşımın temel varsayımları arasında, uygun olmayan bir şekilde depolanan anıların bireyde gelecek yıllarda işlevsel olmayan düşüncelere ve kendilik algisında olumsuz değerlendirmelere sebep olabileceği ihtimalleri yer almaktadır. Shapiro'nun uyumsal bilgi işleme modeline göre bireyi rahatsız eden bir yaşam olayı veya travma sonrası oluşan bilgi tam olarak işlenmediğinde biliş ve algılarda olumsuz bir durum oluşturacaktır (Torun, 2010). Bu nedenle bireyin yaşamında olası yaşayabileceği olumsuz duygulanım durumlarında işlenmeden kalan anıların gelecekte önemli bir etkisi olacaktır. Özellikle de çocukluk döneminde yaşanan travmatik yaşam olayları ve paralelinde oluşan olumsuz düşüncelerin işlenmesi gereken temel anılar olarak bu terapide ele alındığı görülmektedir (Shapiro ve Maxfield, 2002). Anıların duyarsızlaştırılması yöntemleri arasında hızlı göz hareketleri, çift yönlü ses uyarımları veya çift yönlü olarak danışanın diz kapaklarına bir araç ile vurma şeklinde çeşitli teknikler yer almaktadır. 


\section{Emdr Tedavisi Aşamaları}

EMDR terapi yöntemi uygulamaları 8 aşamadan oluşan bir süreci kapsamaktadır. İlk iki aşama iki oturumda tamamlanabilirken diğer aşamalar farklı sayıda oturumda tamamlanabilmektedir (Shapiro, 2016). Bu aşamalar;

Öykü alma aşaması: Danışanın geçmişte var olan problemleri, danışanın EMDR terapiye uygunluğunun değerlendirilmesi, tedavi planı formunun doldurulması ve uygun hedeflerin belirlenmesidir.

Hazırlık aşaması: Danışana bir nevi tedavi süreci ile ilgili eğitimin verildiği aşamadır. Terapi tekniklerinden bahsedilir, kullanılacak duyarsızlaştırma yöntemi danışan tarafından seçilir ve danışana yoğun duygulanım yaşaması durumlarında kullanması için sakinleştirme teknikleri öğretilir.

Değerlendirme aşaması: Çalışılacak hedef anı belirlenerek bu anıya yönelik danışanın olumlu ve olumsuz inançların, danışanın duygularını olumsuz etkileyen tetikleyicilerin, duyguların ve beden duyumların alındığı aşamadır.

Duyarsızlaştırma aşaması: İşlenmemiş olumsuz anının çift yönlü uyarım yolu ile beynin her iki kısmına da işlemenin yapıldığı aşamadır. Amaç, danışanı rahatsız eden anı ile olabildiğince az ilişkilendirmek, danışana içsel gelişim sağlamak, kendisi ve dünya ile ilgili yeni bir bakış kazandırmaktır.

Yerleştirme aşaması: Danışanın terapi süreci sonunda, işlenen anının olumsuz inancın yerine sahip olmak istediği olumlu inancın çift yönlü uyarım yöntemi ile yerleştirilme basamağıdır.

Beden tarama aşaması: Danışan tarafından olumlu inancın bedensel duyum olarak fark edilmesi sağlanarak olası olumsuz beden duyumlarının çift yönlü uyarım yöntemi ile yok edilmeye çalışıldığı aşamadır.

Tamamlama aşaması: Seansın tamamlandığı ve bir sonraki seansın konusunda bilgilendirmenin yapıldığı ayrıca ihtiyaç duyulması halinde rahatlama tekniklerinin kullanıldığı aşamadır.

Yeniden değerlendirme aşaması: Terapist ile danışanın terapi süreci üzerine değerlendirmelerin yapıldığı̆, önceki seans tedavilerinin ele alındığı, yeniden işlenmesi gereken bir anının veya olumsuz durumun olup olmadığı ya da terapi sürecinin sonlandırma kararının alındığı aşamadır.

\section{Tedavi Protokolünde Yer Alan Terimler}

Resim: Danışanın mevcut anısında olayın en kötü kısmını temsil eden rahatsız edici görüntü olarak tanımlanmaktadır. 
Olumsuz inanç (negatif kognisyon): Danışanın olumsuz anıya baktığında kendisine yönelik olumsuz inancinı temsil etmektedir.

Olumlu inanç (pozitif kognisyon): Danışanın terapi süreci sonunda olumsuz anısına yönelik kendisi ile ilgili sahip olmak istediği olumlu inancı temsil etmektedir.

Olumlu inancın geçerliliğgi ( $\mathrm{VoC})$ : Danışanın olumsuz anıya yönelik resmi düşündüğünde olumlu inancın geçerliliğine 1 ile 7 arasında yapmış olduğu puanlamadır.

Duygu: Danışanın anıyı ve olumsuz inancı birlikte düşündüğünde hissettiği duyguları temsil etmektedir.

Öznel rahatsızlık düzeyi (SUD): Danışanın mevcut olumsuz anıyı düşündüğünde kendisini 0 ile 10 arası bir ölçekte ne kadar rahatsız ettiğini belirten kavramdır.

Beden duyumu: Danışanın olumsuz anının yansımalarını bedeninin hangi kısımlarında hissettiğini belirlemek amacıyla kullanılır.

Duyarsızlaştırma: Danışana anıyı ve olumsuz inancını, hissettiği duygu ve bedensel duyumlarını fark etmesi istenerek yapılan işleme çalışmalarıdır.

Yerleştirme: Duyarsızlaştırma sonrasında danışandan anıyı tekrar düşünmesi istenerek, istenilen olumlu inanç ile anının birleştirilmesidir.

Beden tarama: Danışanın o anıyı ve istenilen olumlu inancı düşünmesi istenerek bedeninde olumlu ve olumsuz duyumunun olup olmadığının sorgulanmasıdır.

Güvenli yer oluşturma: Danışanın terapi esnasında ve günlük yaşamında stresi azaltması, kendini iyi hissetmesi amacıyla bir yerin hayal ettirilmesi etkinliğidir.

Tedavi protokolü ve terapi basamaklarının gelen danışanın yaşadığı soruna ve belirlenecek amaca göre şekillendirilmesi, EMDR terapinin önemli arz eden gerekliliklerinden birisidir. Çalışmada bu duruma dikkat edilmiş olup, danışanın yaşadığı soruna yönelik gerçekçi amaçlar belirlenmeye çalışılmıştır. Bu olgu sunumunun amacı, kısa sürede etkin ve işlevsel sonuçlar veren EMDR terapinin, OKB tanısı alan danışana rahatsızlık veren düşünceler üzerinde etkinliğini ortaya koymak ve danışanın kendisini daha iyi hissetmesini sağlamak şeklinde belirlenmiştir.

\section{Yöntem}

Bu araştırmada, nitel araştırma yöntemlerinden biri olan olgu sunumu yöntemi kullanılmıştır. Terapi desteği için başvuru yapan kadın danışan, 22 yaşında üniversite öğrencisidir. Psikiyatrik tanılama sonrası, gerekli bilgilerin danışan tarafından öğrenilmesi sonrasında EMDR terapi uygulanmaya karar verilmiştir. EMDR terapini tanıtımı ve oturum kurallarının danışanla birlikte belirlenmesinin ardından kendisinden terapi sürecine gönüllü katılım sağladığı ve terapi sonrasında elde edilen bilgilerin, bilimsel yayında kullanılmasını içeren onam formunun okunarak imzalanması 
istenilmiştir. Gönüllü onam formu danışan tarafından okunarak imzalanmıştır. Terapi süreci; öngörüşme, yedi oturum ve kontrol seansından oluşmakta olup her bir oturum süpervizyon alınarak yürütülmüştür. Oturumlar rehberlik ve araştırma merkezinde yer alan danışma odasında gerçekleştirilmiştir.

EMDR yaklaşımına göre, travma ile ilgili anı bellekte uygun olmayan bir biçimde depolanır. $\mathrm{Bu}$ geçmiş yaşantı ile ilgili anılar terapide çift yönlü uyarımla işlenir (Oren ve Solomon, 2012). Böylelikle danışanın olumsuz duygu, düşüncelere neden olay (travmasıyla) ile başa çıkması sağlanır. $\mathrm{Bu}$ çalışma da danışanın da istenmeyen düşünceleri ile ilgili travmatik anıları çift yönlü uyarımla işlenmeye çalışılmıştır.

\section{Olgu Sunumu}

22 yaşında üniversite öğrencisi olan danışan, rahatsızlık veren düşüncelerden dolayı öncelikle bir ruh sağlığı uzmanı ile görüşmüşs sonrasında rehberlik ve araştırma merkezimizin ilgili birimine başvurusunu yapmıştır. Kendisi özel bir hastanenin psikiyatri servisine başvurduğunu, bazı testler yapıldığını, olay öyküsü ve düşüncelerinin belirtildiğini, sonrasında yetişkinlere yönelik OKB rahatsızlık derecesini ölçen bir formun uygulandığını belirtmiştir. Danışan kendi isteği ile uygulanan form ve puanını, konulan tanıyı içeren belgeyi paylaşmıştır. Belgede, klinik muayenesinde patolojik, psikotik bulguya rastlanılmadığı, başlangıç düzeyde OKB tanı belirtileri taşıdığına yönelik kısa bir bildirim yer almaktadır. Danışan ile yapılan ön görüşmede kısa bir süre önce ruh sağlığı konularında yardımlaşmaya yönelik popüler bir forum sitesinde tanıştığı bireyin, danışanı ikna ederek poşet içerisinde ekmek kırıntılarına basma, nesnelere zarar verme tarzında yaptırmış olduğu eylemler anlatmıştır. Sonrasında tanıştığı bireyin sosyopat tanısı almış birisi olduğunu öğrenmesine bağlı olarak yaşadığı hayal kırıklığı, yaptığı eylemlerin aklından çıkmaması, aşırı derece duyulan pişmanlık duygusu, aşırı mutsuzluk durumlarının yaşandığını belirtmiştir. Kendini mutsuz hissetmesi ile başlayan sürecin akıl sağlığını yitirme ve çevresindeki hem cinslerinden hoşlanma tarzında rahatsız edici düşüncelere doğru ilerlediğini ve bu düşüncelerin bir anda gelerek kendisini çok rahatsız ettiğini ifade etmiştir. Mevcut olumsuz düşüncelerin yaklaşık üç aydır devam ettiğini vurgulamıştır. Mevcut geliş sebebi, danışan genel durumu, yaşanılan problemin EMDR terapi kriterlerine uygunluğu gibi kriterlerin değerlendirilmesi sonucunda danışanın EMDR terapiye uygun olduğu kanaatine varılmıştır. Sonrasında oturumlara başlama kararı alınmıştır.

\section{Müdahale}

Danışan ile öncelikle doğumundan başlayarak bugüne kadar yaşadığı olumsuz olaylar, travmatik yaşantılar, aile ve çevresel ilişkilerin yapısı ele alındı. Yaşadığı soruna yönelik belirtilerin ne zaman başladığı öğrenildi. Danışanın yaşamında karşılaştığı sorunlarla başa çıkma yöntemleri belirlendi. Danışanın yaşadığı sorun ve terapiye uygunluğu kriteri süpervizör ile birlikte 
değerlendirildi. Bu değerlendirmenin sonucunda danışanın EMDR terapi için uygun olduğu kararına varıldı. Danışana oturumların yapılandırması ve süreci hakkında bilgi verildi. Sonrasında danışma oturumlarında ve günlük yaşam olaylarında stresi, gerginliği azaltması adına adına güvenli yer egzersizi tanıtıldı ve uygulaması yapıldı. Danışanla birlikte terapi planlaması formu dolduruldu. $\mathrm{Bu}$ forma danışanın terapiye geliş sebebi ile suçluluk ve çaresizlik ana olumsuz inançlarından yola çıkarak danışanın ilk anısı, en kötü anısı ve diğer olumsuz anıları ile bunların tetikleyicileri olabilecek durum ve olaylar sırasıyla yazıldı. Sonrasında her anı için EMDR terapi protokolüne uygun birer çalışma kağıdı hazırlandı. Çalışma kağıdında danışanın olaya dair ilk anısı olmak üzere her anı için EMDR terapi protokolünde yer alan; olumsuz inanç, istenilen olumlu inanç, öznel rahatsızlık düzeyi ve olumlu inancın geçerliliği değerlerinin alınması, bedensel duyumlar, çift yönlü göz hareketleri, yerleştirme, beden taraması yöntemleri yer almaktaydı. Yine danışanın tetikleyici olarak belirttiği evde tek başına kaldığında düşüncelerin yoğun bir şekilde gelmesi durumuna yönelik gelecek şablonu oluşturuldu.

Bu yöntemlerin uygulanması sonrasında her anı ve tetikleyici durum için danışan üzerinde vermiş olduğu rahatsızlık dereceleri sıfırlandı. Çalışma formunda yer alan olumsuz anılar işlendikçe rahatsızlık veren düşüncelerin etkisini kaybettiği görüldü. Terapi sonrasında aradan geçen üç hafta sonrasında kontrol seansı yapıldı. Bu seansta danışan geliş sebebi olan rahatsızlık veren hem cinsine yaklaşma, akıl sağlığını kaybetme düşüncelerinin artık eskisi kadar sık gelmediğini ve rahatsız etmediğini belirtti. Aşağıda belirtilen müdahale çalışmalarının ve yapılan oturumların özetlemeleri bulunmaktadir.

Birinci oturum başlangıcında EMDR terapiye dair bilgilendirme yapıldı. Sonrasında danışana terapi süresince ve günlük yaşamında stresi azaltması, kendini iyi hissetmesi amacıyla güvenli yer etkinliği uygulandı. Güvenli yer etkinliği oluşturmada bir sorun yaşanmadı. Danışan etkinliği yaparken bedeninde oldukça fazla rahatlama hissettiğini belirtti. Etkinliğin ardından danışan ile birlikte terapi planlaması formu dolduruldu. Danışan oturumlara gelme sebebi olarak, yeni tanıştığı birisi tarafından ikna edilerek nesnelere zarar verme, ekmek kırıntılarını çiğneme tarzında eylemleri yaptığını, sonrasında bu bireyin sosyopat tanısı almış birisi olduğunu öğrendiğini belirtti. Aldatılma duygusu, yaptığı eylemlerin aklından çıkmaması ve bunların sonucunda yoğun bir şekilde hissedilen pişmanlık ve mutsuzluk duyguları yaşandığını ifade etti. Son üç aylık süreçte mutsuz hissetme ile başlayan sürecin akıl sağlığını yitirme ve çevresindeki hem cinslerinden hoşlanma tarzında rahatsız edici düşüncelere doğru ilerlediğini ve bu düşüncelerin bir anda gelerek kendisini çok rahatsız ettiğini belirtti. Bu düşüncelerin danışanda oluşturduğu ana olumsuz inançlar ise suçluluk ve çaresizlikti. Danışanın günlük yaşamında karşılaştığı sorunları çözmeye yönelik kullandığı ve ona iyi geldiğini belirttiği kaynaklar arasında; kitap okumak, yabancı diziler izlemek, voleybol oynamak, kayak 
yapmak, ibadet etmek, yürüyüş yapmak, müzik aleti çalmak, yabancı dil öğrenme çalışmalarının olduğu ortaya çıkarıldı. Bu durum danışanın kaynaklarındaki zenginliğin iyileşme sürecine katkısının yüksek olabileceği şeklinde değerlendirilebilir. Ardından danışana rahatsızlık veren düşüncelerin tetikleyicileri belirlendi. Danışan terapi hedefi olarak kendisine rahatsızlık veren bu düşüncelerden kurtulmayı belirledi ve kısa bir özetlemenin ardından oturum sonlandırıldı.

İkinci oturumda, EMDR terapinin, çocukluk döneminde yaşanan olumsuz anıların gelecekte karşılaşılan benzer olaylar sonrasında olumsuz düşüncelerin ortaya çıkabilmesine sebep olabileceği anlayışından dolayı (Shapiro ve Maxfield, 2002) ilk anı çalışılmaya karar verildi. Danışan 6 yaşında kardeşi ile birlikte gittiği parkta danışan sallanmaktadır. Danışan kardeşini özellikle uyarmasına rağmen hemen yanındaki salıncakta oturan çocuğun salıncağı kardeşinin yüzüne sert bir şekilde çarpar ve kardeşi yaralanır. Annesi parka gelerek sorumlu olarak danışanı tutar ve ağır söylemlerde bulunur. Danışandan yaşadığı bu anıya yönelik aklına gelen en kötü sahnenin ne olduğu soruldu. Annesinin herkesin içerisinde yüksek bir sesle bağırma anının en kötü sahne olduğunu belirtmiştir. Danışan anıya yönelik yaşamış olduğu öznel rahatsızlık düzeyini 10 üzerinden 5 puan olarak belirlerken, olumsuz inanç olarak, "suçlu birisiyim", istediği olumlu inancı da "masumum" şeklinde belirtti. Olumlu inancın geçerliliğini 7 üzerinden 4 olarak belirtti. Beden duyumu taramasında rahatsızlığı boğazında ve bacaklarında hissettiğini belirtti. Ardından duyarsızlaştırma basamağına geçildi. Hızlı göz hareketleri ile anı işlenmeye başlandı. Gelen akışlar genellikle kardeşine yönelik olup küçükken kardeşinin başına gelen olumsuz olayları içeren sahneleri içermekteydi. Danışan setler ilerledikçe ağlamaya başladı. Olumsuz olayların sorumlusu olarak kendini suçladı. Göz hareketlerinin sonuna doğru olumsuz olayları içeren yaşantıların yerini olumlu yaşantıları içeren anılar almaya başladı. Danışanın duygu ve beden duyumlarından olumlu sahneler gelmeye başlayınca tekrar öznel rahatsızlık düzeyi değeri alındı. Danışan 0 puan verdi. Son bir set yapılarak yerleştirme aşamasına geçildi. Danışana baştaki olayı düşünerek istenilen olumlu inancın geçerliliğinin 1 ile 7 arasında ne kadar doğru geldiği soruldu ve baştaki istenilen olumlu inancın geçerlilik puanının bu kez 6 olduğu belirtildi. Hızlı göz hareketleri ile arzulanan olumlu inanç ile birlikte anı işlenmeye başlandı. Sonrasında tekrar istenilen olumlu inancın geçerlilik değeri soruldu ve 7 cevabı alındı. Güçlendirmek adına bir set daha yapıldı. Ardından danışanda olumlu veya olumsuz beden duyumları soruldu. Olumlu şeyler hissettiği, rahatlamış olduğu, bedeninde iyi duyumlar olduğunu ifade etti. Bunu güçlendirmek adına bir set daha göz hareketi yapıldı. İkinci oturumun kısa bir özetlemesinin ardından oturum sonlandırıldı.

Üçüncü oturumda, danışanın geliş sebebi olan rahatsız edici düşünceler ele alındı. Bu düşüncelerden yoğun ve en rahatsız edici olan hem cinslerimden hoşlanma düşüncesi üzerine konuşuldu. Bu düşünceye yönelik yaşadığı en son olumsuz yaşantı soruldu. Danışan cep telefonunda 
sosyal medyada gezinirken tesadüfi olarak bir kadın mankenin resmini görüyor sonra sayfalar arasında dolaşıp telefonunu bırakıyor. Bir süre geçtikten sonra aklına ben kadınlardan mı hoşlanıyorum düşüncesi geliyor ve bu düşünceden çok rahatsız oluyor. Danışandan bu anıya yönelik en rahatsız edici sahnenin ne olduğu soruldu. Danışan bu düşünceler geldiğinde koltuğun üzerinde öyle çaresizce oturduğu sahnenin çok rahatsız edici olduğunu belirtti. Danışan anıya yönelik öznel rahatsızlık düzeyini 10 üzerinden 8 puan olarak belirlerken, olumsuz inanç olarak, "utanç vericiyim", istediği olumlu inancı da "onurluyum" olarak belirtti. Olumlu inancın geçerlilik düzeyini 7 üzerinden 3 olarak belirtti. Beden duyumu taramasında rahatsızlığı kollarında ve bacaklarında hissettiğini belirtti. Ardından duyarsızlaştırma basamağına geçildi. Hızlı göz hareketleri ile anı işlenmeye başlandı. Gelen akışlar eski erkek arkadaşı ile yaşadığı olumsuz yaşantılar, OKB tanısı almış bir çocuğun videosu, erkek kardeşinin kaldığı yurtta arkadaşlarına yapılan istismar şeklinde başlangıçta olumsuz sahneler geldi. Setler devam ettikçe anne ve babası ile birlikte uyuduğu bir gece, baba ile birlikte yapılan danışanı mutlu eden faaliyetler, danışanın ihtiyaç sahibi birisine yaptığı yardım olaylarını içeren olumlu duygular ve bedensel gevşeme ifadeleri oluştu. Olumlu duyumların geldiği anlaşllınca danışandan tekrar öznel rahatsızlık düzeyi değeri alındı. Danışan 4 puan verdi. Bunun üzerine danışanın öznel rahatsızlık düzeyi sıfırlanıncaya kadar setlere devam edildi. Bu setlerde de genellikle çocukluktan itibaren insanlara yaptığı iyilikleri içeren sahnelerin geldiği görüldü. Daha sonra tekrar öznel rahatsızlık düzeyi alındı. Danışan bu kez 0 puan verdi. Verilen dereceyi güçlendirmek adına son bir set daha yapıldı ve danışan kendisini iyi hissettiğini, şuan düşündüğünde mankenin resminin kendisini rahatsız etmediğini belirtti. Ardından yerleştirme aşamasına geçildi.

Danışana baştaki olayı düşünerek istenilen olumlu inancın 1 ile 7 arasında ne kadar doğru geldiği soruldu ve baştaki istenilen olumlu inancın geçerliliğinin bu kez 5 olduğu belirtildi. Hızlı göz hareketleri ile arzulanan olumlu inanç ile birlikte anı tekrar işlenmeye başlandı. Sonrasında istenilen olumlu inancın geçerliliği soruldu ve 7 cevabı alındı. Güçlendirmek adına bir set daha yapıldı. Ardından danışanda olumlu veya olumsuz beden duyumları soruldu. Olumlu şeyler hissettiği, rahatlamış olduğu, bedeninde iyi duyumlar olduğunu ifade etti. Bunu güçlendirmek adına bir set daha göz hareketi yapıldı. Üçüncü oturumun kısa bir özetlemesinin ardından oturum sonlandırıldı.

Dördüncü oturumda, danışanın en kötü anısı ele alındı. 9 yaşında televizyonda izlediği bir programda kadınların kaş alma durumları anlatıllyor. Danışanda merak edip banyoda kaşlarını almaya çalışıyor ancak bunu beceremiyor. Durum annesi tarafından fark edilince ağır cümleler duyuyor ve cezalandırılıyor. Olumsuz anıya dair en kötü sahnenin banyoda, annesinin kendisine kurmuş olduğu cümlelerin olduğu sahne olarak belirtilmiştir. Danışan anıya yönelik yaşamış olduğu öznel rahatsızlık düzeyini 10 üzerinden 9 olarak belirlerken, olumsuz inanç olarak, "utanç vericiyim", inanmak istediği olumlu inanç olarak "masumum" düşüncesini belirtti. Olumlu inancın geçerliliğini 7 
üzerinden 2 olarak belirtti. Beden duyumu taramasında rahatsızlığı kalbinde ve karnında hissettiğini belirtti. Ardından duyarsızlaştırma basamağına geçildi. Hızlı göz hareketleri ile anı işlenmeye başlandı. Gelen akışlar annenin hastaneye kontrole kadar götürmesi, işittiği sözler, okula bir hafta boyunca gitmemesi şeklindeydi. Danışandan tekrar öznel rahatsızlık düzeyi alındı. Danışan 6 puan verdi. Bunun üzerine danışanın rahatsızlık derecesi sıfırlanıncaya kadar setlere devam edildi. Bu setlerde de genellikle babası ile annesi arasında danışanın şahit olduğu tartışmalar, boşanma noktasına gelen konular ve konuşmalar, olumsuz anılar geldi. Setlerin sonuna doğru çocukluk arkadaşı ile olan hatıraları geldi. Tekrar öznel rahatsızlık düzeyi alındı. Danışan bu kez de 4 puan verdi. Danışanın bu cevabının ardından oturum sonuna gelindiği için anının kendisini kötü hissettirip hissettirmediği soruldu. İyi olduğunu söyledi. Danışanın genel durumu iyi olduğu anlaşılınca rahatlama egzersizi ve güvenli yer etkinliği yapıldı ve sonraki oturumda mevcut anıdan devam edileceği belirtildi. Oturum sonlandirıldi.

Beşinci oturumda, yarım kalan anının tamamlanması protokolü uygulandı. Yarıda kalan anıya yönelik en kötü resmin aynı olup olmadığı soruldu. Olumsuz inanç ile istenilen olumlu inancın aynı olup olmadığı sorgulandıktan sonra bir değişme olmadığı belirtildi. Sonra danışana olayın nasıl olduğu soruldu? Bir önceki oturum sonrasında eve gittiğinde daha iyi hissettiğini, kendisinin masumiyetine olan inancının arttığını belirtti. Danışandan tekrar olaya odaklanmasını ve şuan da o olayın kendisini ne derece rahatsız ettiği soruldu. Öznel rahatsızlık düzeyi, bu kez 3 puan olarak ifade edildi. Göz hareketlerine devam edildi. Sahnelerde danışanın geçmişten gelen akademik sportif eylemlerde elde ettiği başarılar vardı. Olumsuz anlamda sahnelerin gelmediği gözlemlendi. Bu olumlu aktarımlar sonrasında tekrar öznel rahatsızlık düzeyi, değeri alındı. Danışan bu kez 0 puan verdi. Masum olduğuna yönelik inancın yüksek olduğunu belirtti ve güçlendirmek adına son bir set yapılarak yerleştirme basamağına geçildi. Danışana baştaki olayı düşünerek istenilen olumlu inancın 1 ile 7 arasında ne kadar doğru geldiği soruldu ve baştaki olumlu inancın geçerliliğinin bu kez 7 olduğu belirtildi. Küçük bir çocuk olarak yanlış bir şey yapmadığını, annesinin bu yaklaşımını hak etmediğini belirtti. Olumlu inancın geçerliliğini güçlendirmek adına son bir set daha yapıldı ve burada da benzer olumlu ve masumiyet içerikli düşünce ve sahnelerin geldiği gözlemlendi. Ardından danışanda olumlu veya olumsuz beden duyumları soruldu. Olumlu şeyler hissettiği, kendisini haklılığın vermiş olduğu rahatlığı bedeninde hissettiğini ifade etti. Bunu güçlendirmek adına bir set daha göz hareketi yapıldı. Oturum kısa bir özetlemenin ardından sonlandırıldı.

Altıncı oturumda, danışanın ilk anısından itibaren hatırladığı kendisine yönelik suçluluk ve çaresiz hissettiği diğer olumsuz anısı ele alındı. Danışan görüştüğü erkek arkadaşının aralarında hiçbir sorun yokken bir anda iletişimi kopardığını, ona hiçbir şekilde ulaşamadığını ve kendisini çok kötü hissettiğini belirtti. Anıya yönelik olumsuz sahnenin, bir gün yaklaşık bir saat boyunca telefon 
ekranına bakıp beklediği sahne olduğunu belirtmiştir. Danışan anıya yönelik yaşamış olduğu öznel rahatsızlık düzeyini, 10 üzerinden 3 puan olarak belirlerken, olumsuz inanç olarak, "suçluyum", inanmak istediği olumlu inanç olarak "masumum" düşüncesini belirtti. Olumlu inancın geçerliliğini, 7 üzerinden 5 olarak belirtti. Beden duyumu taramasında rahatsızlı̆̆ kalbinde hissettiğini belirtti. Ardından duyarsızlaştırma basamağına geçildi. Hızlı göz hareketleri ile anı işlenmeye başlandı. Gelen sahneler arasında görüştüğü bireyle yaşadığı güzel anılar vardı. Sonrasında danışanın annesinin o kişiye yönelik eleştirileri ve annesinin haklı olduğuna dair söylemleri geldi. Benzer durumu yaşayan bir arkadaşının yaşadıklarını anlattı. Sonrasında ailesi ile yaşadığı olumlu anılar hatırlandı. Olumlu aktarımlar sonrasında tekrar öznel rahatsızlık düzeyi alındı. Danışan bu anının kendisini çok fazla rahatsız etmediğini söyleyerek rahatlıkla 0 puan verebileceğini söyledi. Güçlendirme seti yapıldıktan sonra yerleştirme basamağına geçildi. Danışana baştaki olayı düşünerek olumlu inancın, 1 ile 7 arasında ne kadar doğru geldiği soruldu ve baştaki olumlu inancın geçerliliğinin, bu kez 7 olduğu belirtildi. Yaşadığı bu anının kendisini fazla rahatsız etmediğini tekrar vurguladı. Bunun üzerine olumlu istenilen inancı güçlendirmek adına son bir set daha yapıldı ve beden taramasına geçildi. Beden taramasında olumlu duyumların fazla olduğu gözlemlendi. Güçlendirmek adına bir set daha göz hareketi yapıldı. Kısa bir özetleme yapılarak oturum sonlandirıldı.

Yedinci oturumda, terapi planlaması formunda yer alan rahatsız eden düşüncelerin artmasını tetikleyen durum çalışıldı. Tetikleyici durum gelecek şablonu çalışması ile ele alındı. Evde uzun süre tek başına kaldığında düşüncelerin yoğun bir şekilde geldiğini ve kötü hissettiğini belirtti. Gelecek bir zamanda annesi ve kardeşinin babasına yanına gitme ihtimali olduğu durumu da öğrenilince danışanla birlikte gelecekte bu duruma yönelik bir senaryo oluşturuldu. Gelecek şablonu oluşturulurken danışanın rahatsız olduğu noktalar setler yapılarak işlendi. Uyarım setleri ile danışanın rahatsızlıklar işlendi ve bu rahatsızlıklar ortadan kaldırıldı. Bu oturumla birlikte danışanla, terapi planlaması formunda yer alan tüm anılar işlendi. Sonrasında danışanla birlikte yapılan seansların değerlendirmesi yapıldı. Danışan artık olumsuz düşüncelerin eskisi kadar rahatsız etmediğini ve eski sıklıkta gelmediğini belirtti. Ders başarısında düzelmeler olduğunu, arkadaşları ile daha sağlıklı iletişim kurduğunu, kendini iyi hissettiğini belirtti. Kontrol seansına gelmek üzere üç hafta sonrasina randevu verildi.

Kontrol oturumunda, geçen üç haftalık süreçte danışan rahatsız edici düşüncelerin artık aklına gelmediğini ve herhangi bir olumsuz duygulanım yaşamadığını belirtti. Yaşamında pozitif anlamda güzel şeyler olduğunu, sabahları daha mutlu uyandığını belirtti. Rahatsız edici düşüncelerden kurtulmak olan terapi hedefinin gerçekleştiği görüldü. 


\section{Tartışma}

Bireylerin geçmiş yaşantılarında sağlıklı bir şekilde işlenmeyen anıları ilerleyen zamanlarda farklı psikolojik rahatsızlıklara sebep olabilmektedir. EMDR terapi yaklaşımında da travmatik anılar diğer anılarla birleşmesi sonucunda işlevsel olmayan tarzda davranış, düşünce ve duyguların ortaya çıkmasına sebep olabilmektedir. Bu çalışmada, danışanın olumsuz ana düşüncelerinden yola çıkarak, ilk anısı, geliş nedeni, en kötü anısı, diğer anıları ve tetikleyici durumu ele alındı. Tüm bu anılar çalışma kağıdına ayrı ayrı yazılarak terapi protokolünde yer alan tüm basamaklar uygulandı. Danışana uygulanan çift uyarımlı göz hareketleri sonucunda artık kendisine rahatsızlık veren düşüncelerin onu rahatsız etmediği görüldü. Yaşamında olumlu gelişmeler olduğu, mutluluk düzeyinde artış olduğu belirtildi. Olgu sunumunda gözlemlenen iyileşme sürecinin yapılan bazı araştırma sonuçları ile benzerlik taşıdığı görülmektedir. Pozza., Mazzoni, Neri, Bisciglia, Mela, Fernandez ve Dettore (2014), üç farklı OKB tanısı almış olan hastalardan birisine sadece EMDR terapi, diğerine bilişsel davranışçı yaklaşımla birlikte EMDR terapi, en son danışana sadece görüşülmüş olup herhangi bir terapi metodu uygulanmamıştır.

Yapılan çalışmalar sonucunda sadece EMDR terapiyi alan danışanın iyileşme belirtilerinde hızlı bir ilerleme olduğu gözlenmiştir. Cusimano (2018), ergenlerde emdr terapinin OKB belirtilerinde etkililiği üzerine yapmış olduğu çalışmada, 13 yaşındaki bir öğrenciye, toplam on beş oturum uygulamıştır. Yapılan terapi sonucunda, öğrencinin OKB semptomlarında önemli bir azalma olduğunu belirtmiştir. Kennan, Farrell, Kennan ve Ingham (2018), daha öncesinde farklı terapi tekniklerinin uygulandığı OKB tanısı bulunan sekiz danışanda EMDR terapi uygulamaya karar vermişlerdir. Yapılan çalışmalar sonucunda danışanlar, kendilerine rahatsızlık veren düşüncelerde azalma olduğunu belirtmişlerdir. Ayrıca sunulan olguda yapıldığı gibi ayrıntılı psikiyatrik değerlendirme ve tanısal netliğin ardından, EMDR uygulaması yapılmasının faydalı olacağı düşünülmektedir. Yapılan araştırmalar ve bu olgu sunumu çalışması, EMDR terapinin OKB tanısı alan bireylerde iyileşmeye katkı sağlayabileceğini göstermektedir. Yine danışanlarda, kısa sürede ve yüksek seviyede iyileşme belirtilerinin görülmesi gelecekte benzer sorunu yaşayan bireylere yönelik yapılabilecek terapi çalışmalarında EMDR terapinin, katkısının yüksek düzeyde olabileceğini göstermektedir.

EMDR, her yaş için kullanılabilen "uyarlanabilir bilgi işleme modeline" dayanmaktadır (Solomon ve Shapiro, 2008) ve özü, verimsiz deneyimler ve depolanan düşüncelerdeki değişimi içermektedir (Maroufi, Zamani, Izadikhah, Marofi, O'Connor, 2016). Bundan dolayı araştırmanın sonuçlarından yola çıkarak okullarda yaşanan ruhsal sorunlara kısa süreli müdahale de EMDR'nin uygulanabileceği düşünülebilir. Bu müdahale sonucunda bireyin ruhsal sağlığına kavuşması, 
gelişimsel rehberlik programının güvenli sağlıklı hayat bölümüne katkı sağlayabileceği şeklinde değerlendirilebilir.

\section{Sonuç}

Çalışmanın sınırlılıkları arasında danışanın başarılı bir öğrenci olmasından dolayı bazı oturumlarda okuldaki derslerden aldığı sınav puanlarının etkisini aşırı hissetmesi sonucu oturum başlangıçlarında konsantrasyon sorunu yaşaması ve buna müdahale etmede yaşanılan güçlük, oturum başlangıcında obsesif belirtilerin ağırlığına yönelik bir değerlendirme ölçeği kullanılması gösterilebilir. Bu çalışma da, EMDR terapinin, OKB yaşayan bireyin sorununu azaltmada etkili olduğu sonucuna ulaşılmıştır. Dolayısıyla EMDR terapinin kısa bir sürede danışanın yaşadığı sorunları azaltmada etkili olduğu söylenebilir. Farklı OKB belirtileri yaşayan bireylerde, EMDR uygulamasının yapılması, bu yöntemin etkililiği hakkında daha net bulguların elde edilmesini sağlayacaktır.

\section{Kaynaklar}

Anderson, R.A., and Rees, C.S. (2007). Group versus individual cognitive-behavioural treatment for obsessive-compulsive disorder: A controlled trial. The Journal of Behavior Therapy and Experemental Psychiatry, 45, 123-137.

Barker, R.T., and Barker S.B. (2007). The use of emdr in reducing presentation anxiety. Journal of EMDR Practice and Research, 1(2), 100-108.

Beşiroğlu, L. (2016). Obsesif kompulsif bozuklukta bilişsel nöropsikolojik model bağlamında tedavi yanıtını ve direncini anlamak. Türk Psikiyatri Dergisi, 27(3), 1-9.

Clark, D.A., Taylor, S. (2009). The transdiagnostic perspective on cognitive-behavioral therapy for anxiety and depression: new wine for old wineskins? Journal of Cognitive Psychotherapy, 23(1), 60.

Cusimano, A. (2018). EMDR in the treatment of adolescent obsessive-compulsive disorder: A case study. Journal of EMDR Practice and Research, 12(4), 242-254.

Duman, R. N., Bayram, S. ve Demirtaş, B. (2018). EMDR: Olgu sunumları. Türkiye Bütüncül Psikoterapi Dergisi, 1(1), 142-164.

Fisher, P.L., and Wells, A. (2005). Experimental modification of beliefs in obsessive compulsive disorder: a test of the metacognitive model. The Journal of Behavior Therapy and Experemental Psychiatry, 43, 821-829.

Kavakçı, (2014). Ruhsal travma tedavisi için emdr. Ankara: HYB Yayınları. 
Kennan, P., Farrell, D., Kennan, L., and Ingham, C. (2018). Treating obsessive compulsive disorder (OCD) using eye movement desensitisation and reprocessing (EMDR) therapy: An ethnophenomenological case series. International Journal of Psychotherapy, 22, (3), 74-91

Konuk, E., Knipe, J., Eke, I., Yuksek, H., Yurtsever, A., and Ostep, S. (2006). The effects of eye movement desensitization and reprocessing (EMDR) therapy on posttraumatic stress disorder in survivors of the 1999 Marmara, Turkey, earthquake. International Journal of Stress Management, 13, 291-308.

Krupnik, V. (2018). Differential Effects of an evolutionary-based emdr therapy on depression and anxiety symptoms: A case series study. Journal of EMDR Practice and Research, 12(2),47-57.

Maroufi, M., Zamani, S., Izadikhah, Z., Marofi, M., and O'Connor, P. (2016). Investigating the effect of eye movement desensitization and reprocessing (EMDR) on postoperative pain intensity in adolescents undergoing surgery: A randomized controlled trial. J Adv Nurs., 72(9), 2207-17.

Maher A.R., and Theodore, G. (2012). Summary of the comparative effectiveness review on off-label use of atypical antipsychotics. Journal Manage Care Pharm., 18(5), 1-20.

Marsden, Z., Lovell, K., Blore, D., Ali, S., and Delgadillo, J. (2018). A randomized controlled trial comparing EMDR and CBT for obsessive-compulsive disorder. Clinical Psychology and Psychotherapy, 25(1), 10-18.

Nazari, H., Momeni, N., Jariani, M., and Tarrahi, M. J. (2011). Comparison of eye movement desensitization and reprocessing with citalopram in treatment of obsessive-compulsive disorder. International Journal of Psychiatry in Clinical Practice, 15(4), 270-274.

Oren, E., and Solomon, R. (2012). EMDR therapy: An overview of its development and mechanisms of action. Eur Rev Appl Psychol., 62(4), 197-203.

Pozza, A., Mazzoni, G. P., Neri. M. T., Bisciglia, R., La Mela, C., Fernandez, I., and Dettore, D. (2014). Tackling trauma to overcome OCD resistance (The TTOOR Florence trial) Efficacy of EMDR plus CBT versus CBT alone for inpatients with resistant obsessive compulsive disorder. Protocol for a randomized comparative outcome trial. American Journal of Applied Psychology, 2(5), 114-122.

Roiser, J.P., and Sahakian, B.J. (2013) Hot and cold cognition in depression. CNS Spectrums Journal, 18, 139-149.

Shapiro, F., and Maxfield, L. (2002). Eye movement desensitization and reprocessing (EMDR): Information processing in the treatment of trauma. Journal of Clinical Psychology, 58, 933- 946.

Shapiro, F. (2007). EMDR, Adaptive information processing, and case conseptualization. Journal of EMDR Practice and Research, 1(2), 68-87. 
Shapiro, E. (2012). Emdr and and early psychological intervention following trauma. European Review of Applied Psychology, 62, 241-251.

Shapiro, S. (2016). EMDR: Göz hareketleri ile duyarsızlaştırma ve yeniden işleme temel prensipler, protokoller ve prosedürler (Şahzade, M. ve Sansoy, I., Çev.) İstanbul: Okuyan Us Yayınları.

Sinici, E., Aydın, S. ve Öznur, T. (2018). Tedaviye dirençli obsesif kompulsif bozuklukta pozitif psikoterapi etkili olabilir mi? Bir olgu sunumu. Klinik Psikiyatri Dergisi, 21(4), 407-413.

Solomon, R.M., and Shapiro, F. (2008). EMDR and the adaptive information processing model potential mechanisms of change. Journal EMDR Practice and Research, 2(4), 315-25.

Torun, F. (2010). Vajinismusun emdr yöntemi ile tedavisi: İki olgu sunumu. Türk Psikiyatri Dergisi, 21(3), 243-248.

Van den Berg, D.P, and Van der Gaag, M. (2012). Treating trauma in psychosis with EMDR: A pilot study. The Journal of Behavior Therapy and Experemental Psychiatry, 43, 664-71.

Yörük, P. ve Tosun, A. (2015). Metacognitive model of obsessive compulsive disorder. Psikiyatride Güncel Yaklaşımlar Dergisi, 7(2) , 190-207.

\section{ORCID}

Serkan Cengiz (D) https://orcid.org/0000-0001-9070-6338

Âdem Peker (D) https://orcid.org/0000-0002-3594-9166

\section{Extended Summary}

\section{Effect of Emdr Therapy on Obsessive Compulsive Disorders: Case Report}

The eye movement desensitization and reprocessing (EMDR) therapy which has been used in the treatment of different types of psychological disorders in recent years, stands out as a therapy technique used in the treatment dimension of obsessive compulsive disorders. In this study, it was aimed to eliminate the disorder by applying EMDR therapy steps to the obsessive compulsive disorder. The case report method, one of the qualitative research methods, was used in this study.

A university student was diagnosed with an initial level of obsessive-compulsive disorder, with no pathological or psychotic findings in his clinical examination. With the client, negative events, traumatic experiences, family and environmental relations were discussed. Then the symptoms for the problem she was experiencing began to be found. The problem experienced by the client and the criteria for compliance with the therapy were evaluated together with the supervisor. The client was determined to be eligible for EMDR therapy. The therapy planning form was filled out with the client. Then a working paper was prepared for each memoir in accordance with the EMDR therapy protocol. 
During the first session, the client was given a safe place activity in order to reduce stress and feel better during the therapy and in his / her daily life. After the event, the therapy planning form was filled in with the client. The reason she came to the consulting sessions was because she was convinced by someone she had just met that he had taken actions in the manner of damaging objects, chewing breadcrumbs, and then learned that this individual was someone who had been diagnosed as a sociopath. In the last three months, the process started with feeling unhappy, losing her sanity and liking her surroundings in the way of disturbing thoughts, and these thoughts came at a time when she said that she was very uncomfortable. Then the triggers of the thoughts that irritated the client were determined. The client determined to get rid of these uncomfortable thoughts as a therapy goal, and after a brief recap, the session was terminated.

The second session dealt with the client's first memory. In the park where the counsellor goes with her 6-year-old brother, the counsellor shakes. The child sitting on the swing right next to him hits her brother hard in the face and her brother is injured, although the counsellor specifically warns his brother. Her mother comes to the park and holds the client accountable and makes heavy rhetoric. While the client determined the level of discomfort she experienced towards the memory as a score of 5 out of 10, she stated the negative thought, 'I am a criminal', and the positive thought he wanted to believe, 'I am innocent'. She stated her level of faith in her validity of positive belief as 4 out of 7 . Quick eye movements began to process the moment. As a result of the processing, the degree of discomfort caused by the moment was reset and the session was terminated.

The third session dealt with disturbing thoughts that were the reason for the client's arrival. These thoughts were discussed intensely and most disturbing about the thought of liking my fellow men. She was asked about the most recent negative experience she had towards this idea. While the client determined the level of discomfort she had experienced towards the memory as a score of 8 out of 10, she stated the thought of 'I am shameful' as a negative thought, and 'I am honoured' as a positive thought she wanted to believe. She stated her level of faith in his validity of positive belief as 3 out of 7. Quick eye movements began to process the moment. The sets were continued until the client's discomfort rating was reset.

In the fourth session, the client's worst memory was addressed. A program she watched on $\mathrm{TV}$ at the age of 9 describes the status of women getting eyebrows. At the client, she wonders and tries to get his eyebrows in the bathroom, but she can't. When the situation is noticed by her mother, she is given heavy sentences and punished. In determining the level of discomfort the client experienced towards the memory as 9 out of 10, she stated the thought of 'I am shameful' as negative thinking, 'I am innocent' as positive religion she wanted to believe. She stated her validity of positive belief level 
as 2 out of 7. Quick eye movements began to process the moment. The sets were continued until the client's discomfort rating was reset.

In the fifth session, the protocol of completing the half-time moment was implemented. The client was asked to focus again on the incident and to what extent that incident is bothering her now. The Sud value was expressed this time as three points. Eye movements resumed. The scenes featured the client's achievements in academic sporting acts from the past. It was observed that scenes in negative terms did not arrive. After these positive transfers, the Sud value was taken again. The client gave 0 points this time. She stated that the belief in her innocence was high and a final set was made to strengthen it and the placement step was taken. The client was asked how accurate the desired positive thought was between 1 and 7 considering the initial incident and the initial validity of positive belief score was 7 this time. A final set was made to strengthen the session.

The sixth session dealt with the client's guilt towards her, which she remembered from her first memory, and her other negative memory of feeling helpless. While the client determined the level of discomfort she had experienced towards the memory as a score of 3 out of 10, she stated 'I am guilty' as a negative thought, and 'I am innocent' as a positive thought she wanted to believe. She stated her level of faith in her validity of positive belief as 5 out of 7. Quick eye movements began to process the moment. The sets were continued until the client's discomfort rating was reset.

In the seventh session, the condition that triggered the increase of uncomfortable thoughts contained in the form of therapy planning was studied. The trigger case was addressed by the future template study. She stated that when she was alone at home for a long time, thoughts came intensely and she felt bad. When it was learned that her mother and brother were likely to go to her father at a future time, a scenario was created for this situation in the future with the client. When creating the future template, the points that the client was uncomfortable with were processed by making sets.

During the control session, she stated that during the past three weeks, the client no longer had any disturbing thoughts in her mind and did not experience any negative emotions. She stated that there are positive things in her life and that she wakes up happier in the morning. The goal of the therapy, which is to get rid of uncomfortable thoughts, was realized. 